\title{
PROTOCOL DEVELOPMENT FOR PURIFICATION AND CHARACTERIZATION OF SUB-FOSSIL INSECT CHITIN FOR STABLE ISOTOPIC ANALYSIS AND RADIOCARBON DATING
}

\author{
G W L Hodgins ${ }^{1,2} \bullet \mathrm{J} \mathrm{L} \mathrm{Thorpe}^{3} \bullet \mathrm{G} \mathrm{R} \mathrm{Coope}^{4} \bullet$ R E M Hedges ${ }^{1}$ \\ ABSTRACT. Reliable radiocarbon dating depends upon well-defined samples. We have been investigating whether or not \\ reliable ${ }^{14} \mathrm{C}$ dates can be obtained directly from sub-fossil insect cuticle or biochemical fractions derived from it. Initial carbon \\ and nitrogen stable isotope measurements on sub-fossil insect chitin from species with known feeding behaviors found within \\ a single site (St Bees, Cumbria) clustered in a manner reminiscent of trophic level effects seen in terrestrial ecosystems. \\ Although this finding implied some chemical stability, the measurement of $\mathrm{CN}$ ratios from the same samples indicated com- \\ positional variability. In addition, ${ }^{14} \mathrm{C}$ dates obtained from these same samples were different from dates obtained from plant \\ macrofossils found at the same depth. We have experimented with protocols designed to biochemically reduce chitin to its \\ principle carbohydrate component glucosamine with the aim of using this compound to generate reliable ${ }^{14} \mathrm{C}$ dates. Solvent \\ extractions of sub-fossil chitin were carried out to remove both endogenous and exogenous lipid-soluble materials. Base \\ hydrolysis reactions designed to extract polypeptides retained surprisingly high levels of contaminating amino acids. Protein- \\ ase K enzyme treatment had little affect on the level of amino acid contamination. Strong acid hydrolysis reactions designed \\ to depolymerize chitin to glucosamine yielded only $5 \%$ glucosamine. Clearly alternative methods of chitin depolymerization \\ must be identified before the purification and ${ }^{14} \mathrm{C}$ dating of glucosamine from sub-fossil chitin becomes practical.
}

\section{INTRODUCTION}

The sub-fossil remains of temperature-sensitive insects, predominantly Coleoptera, can be used to generate high resolution palaeoclimate data (Atkinson et al. 1987; Aalbersberg and Litt 1998; Coope et al. 1998). Currently, radiocarbon measurements from associated organic material rather than the insect remains are used to fix the climate data in time. This study investigates the feasibility of directly dating insect remains, so that environmental and time data can be derived from the same material.

The insect cuticle is formed from a complex secretion containing lipids, proteins, and carbohydrates (Richards 1978). The principal component of the cuticle is the carbohydrate polymer chitin. This is hardened by sclerotization, a process resulting in cross-link formation between proteins and carbohydrates within the structure (Peter et al. 1986). Miller et al. (1993) studied the composition of Quaternary Coleoptera remains using chemical tests for primary amines and $\mathrm{N}$-acetylglucosamine: protein content appeared to drop more quickly than chitin. Stankiewicz et al. (1997a) using analytic pyrolysis-GC-MS, found well-preserved cuticle within Pleistocene deposits, and demonstrated chitin-derived fragments within the remains of 25-million-year-old fossil insects (Stankiewicz et al. 1997b)

Initial studies using accelerator mass spectrometry (AMS) measurements on insect remains showed significant differences between the dates obtained for insects and those obtained the from surrounding macrofossils (Elias and Toolin 1990; Elias et al. 1991). The reason for the offset was unclear, and the problem obscured by the possibility of taphonomic mixing. A recent study (Walker et al. 2001)

\footnotetext{
${ }^{1}$ Oxford Radiocarbon Accelerator Unit, Research Laboratory for Archaeology and the History of Art, 6 Keble Road, Oxford, United Kingdom OX1 3QJ.

${ }^{2}$ Corresponding author. Current address: CAIS, University of Georgia, 120 Riverbend Rd., Athens, Georgia 30602 USA. Email: ghodgins@arches.uga.edu.

${ }^{3}$ School of Geography, University of Oxford, Mansfield Road, Oxford, UK, OX1 3TB

${ }^{4}$ Centre for Quaternary Research, Department of Geography, Royal Holloway, University of London, Egham, Surrey, United Kingdom TW20 0EX
}

(C) 2001 by the Arizona Board of Regents on behalf of the University of Arizona Radiocarbon, Vol 43, Nr 2A, 2001, p 199-208

Proceedings of the 17 th International ${ }^{14} \mathrm{C}$ Conference, edited by I Carmi and E Boaretto 
compared AMS dates obtained from insect remains, plant macrofossils, and bulk organic materials, and found insect-derived dates systematically differed from the dates from the stratigraphically associated material.

The chemical pretreatments used for the AMS ${ }^{14} \mathrm{C}$ dating studies by Elias and Toolin (1990), Elias et al. (1991), and Walker et al. (2001) were minimal, no doubt partially because of limited quantities of starting material.

Marine arthropod and insect chitins have been studied as possible source materials for carbon and nitrogen stable isotope studies. Feeding experiments conducted by DeNiro and Epstein (1981) demonstrated a link between diet and both carbon and nitrogen stable isotope ratios in macromolecular insect chitin. Schimmelmann and DeNiro (1986a) developed an ion-exchange chromatography protocol to purify D-glucosamine, the deacetylated monomer from marine arthropod chitin hydrolysates. They found that D-glucosamine $\delta^{13} \mathrm{C}$ values from marine arthropods were on average $9.1 \%$ o heavier than the same material from terrestrial arthropods, and that trophic level shifts occurred in $\delta^{15} \mathrm{~N}$ values of D-glucosamine from arthropods within marine ecosystems (Schimmelmann and DeNiro 1986b). Significantly, $\delta^{15} \mathrm{~N}$ levels within D-glucosamine purified from insect chitin was found to be about $12 \%$ lower than $\delta^{15} \mathrm{~N}$ levels within the muscle mass.

We have been investigating how chemical pretreatment protocols (Table 1) affect sub-fossil chitin and alter both the carbon and nitrogen stable isotope values and AMS dates derived from it. This study has been conducted using samples from the same site as described in Walker et al. as well as from Redkirk Point, another ${ }^{14} \mathrm{C}$ dated, insect-rich deposit. These experiments are directed toward producing and defining chitin fractions amenable to subsequent chromatographic purification by high $\mathrm{pH}$ anion exchange chromatography (also see Hodgins et al. 2001). The ultimate objective is to isolate carbohydrate monomers from chitin in quantities sufficient for ${ }^{14} \mathrm{C}$ dating.

Table 1 Chitin chemical pretreatment protocols

\begin{tabular}{|c|c|c|c|}
\hline Study & $\begin{array}{l}\text { Elias et al. } \\
\text { (1991) }\end{array}$ & $\begin{array}{l}\text { Walker et al. } \\
(2001)\end{array}$ & Schimmelmann and DeNiro (1986a) \\
\hline Objective & ${ }^{14} \mathrm{C}$ dating & ${ }^{14} \mathrm{C}$ dating & $\mathrm{C}$ and $\mathrm{N}$ stable isotopes \\
\hline Starting material & $\begin{array}{l}\text { Sub-fossil } \\
\text { insect remains }\end{array}$ & $\begin{array}{l}\text { Sub-fossil } \\
\text { insect remains }\end{array}$ & Modern marine arthropod cuticle \\
\hline Purified material & $\begin{array}{l}\text { Macromolecular } \\
\text { chitin }\end{array}$ & $\begin{array}{l}\text { Macromolecular } \\
\text { chitin }\end{array}$ & $\begin{array}{l}\text { The chitin-derived monomer } \\
\text { glucosamine- } \mathrm{HCl}\end{array}$ \\
\hline Starting quantity & Milligrams & Milligrams & Grams \\
\hline Protocol & $\begin{array}{l}\text { Acid treatment? } \\
\text { Pentane extraction } \\
\text { Hot water wash }\end{array}$ & $\begin{array}{l}\text { Waterwash } \\
0.5 \mathrm{NHCl} @ \\
80{ }^{\circ} \mathrm{C} 8 \mathrm{hr} \\
\text { water wash }\end{array}$ & $\begin{array}{l}2 \mathrm{~N} \mathrm{HCl} @ 22{ }^{\circ} \mathrm{C} 24 \mathrm{hr} \text { water wash } \\
1 \mathrm{~N} \mathrm{NaOH} @ 100^{\circ} \mathrm{C} 1 \mathrm{hr} \text { water wash } \\
7 \mathrm{~N} \mathrm{HCl} @ 100^{\circ} \mathrm{C} 4 \mathrm{hr} \text { ion exchange } \\
\text { chromatography }\end{array}$ \\
\hline
\end{tabular}

\section{MATERIALS AND METHODS}

\section{Insect Remains, Carex ssp. Seeds, and Bulk Organic Material}

The insect remains and Carex ssp. seeds were recovered from a Quaternary peat deposits near St Bees, Cumbria, UK National Grid Reference NX965114, and Redkirk Point, Dumfrieshire, UK National Grid Reference NY301652. The St Bees section, was bounded by ${ }^{14} \mathrm{C}$ dates of $12,560 \pm$ $100 \mathrm{BP}$ and 11,500 $\pm 120 \mathrm{BP}$ from bulk organic material. The 40-cm-thick section, (thinned down from $50 \mathrm{~cm}$ when sampled by Walker et al. [2001]) was sampled in 5-cm layers. The Redkirk Point 
deposit, considered homogeneous, was dated at 11,205 $\pm 177 \mathrm{BP}$, again from bulk organic material. Both sites are described in Atkinson et al. (1987), and the Redkirk Point site described extensively in Bishop and Coope (1977).

Two-kilogram batches of the deposits were wet sieved through a 1-mm mesh, and the retained portion resuspended in water. Insect fragments and Carex ssp. seeds were picked from the suspension using tweezers. Fifteen to $20 \mathrm{mg}$ of Carex ssp. seeds recovered from each five centimeter layer were chemically pretreated as cellulosic material using ORAU standard protocol (Hedges et al. 1989). The Redkirk Point peat was devoid of identifiable plant remains. Consequently, small twigs or possibly rootlets $(<2 \mathrm{~mm}$ diameter) were collected, macerated with a scalpel, and pretreated as cellulose using the ORAU standard protocol.

The diversity and abundance of Coleopteran species varied within different layers of the St Bees section. To obtain sufficient quantities for stable isotopic analysis and dating, species in each 5-cm layer were pooled according to feeding behavior. Only Carabids (terrestrial scavengers) and Dytiscids (aquatic carnivores) were recovered throughout the section in large enough quantities for isotopic analysis, and even then only after pooling adjacent sections. The lower layers of the section were richer in remains and from these, the terrestrial herbivores Adoxus obscurus, and Barynotus squamosus, and the aquatic herbivore Donacia versicolorea, were recovered in sufficient quantities to allow species-specific stable isotope measurements.

The initial chemical pretreatment began with deionized water-washed lyophilized remains. These were extracted sequentially with methanol, methanol:chloroform 2:1, chloroform, and then lyophylized. The remains were then suspended in $1.0 \mathrm{~N} \mathrm{HCl}$ for $3 \mathrm{hr}$ at room temperature, washed repeatedly with deionized water, and lyophylized. Elemental analysis, stable isotope measurements, and ${ }^{14} \mathrm{C}$ dates were obtained for these samples.

Further protocol development was carried out on the mass of unidentified insect remains from the St Bees site, and species recovered from the Redkirk Point peat deposit. These were predominantly the polyphagous weevil Otiorhynchus nodosus (see Morris 1997). The initial stage of the pretreatment is described above. This was followed by an incubation in $1 \mathrm{~N} \mathrm{NaOH}$ at $100{ }^{\circ} \mathrm{C}$ for $3-12 \mathrm{hr}$ in order to remove polypeptides within the cuticle structure. The remaining solids were washed repeatedly with deionized water and then lyophylized. In some preparations, Proteinase K enzyme (10U/mg) was added at an enzyme to substrate ratio of 1:40 (either before or after the $\mathrm{NaOH}$ treatment) to enhance deproteinization. Samples destined for AMS measurement were treated again with $1 \mathrm{~N} \mathrm{HCl}$ for 30 minutes, washed repeatedly with deionized water, lyophilized and then combusted. Samples destined for chitin hydrolysis followed by high $\mathrm{pH}$ ion exchange chromatography, amino acid analysis, and MALDI-TOF MS were treated with $7 \mathrm{~N} \mathrm{HCl}$ at $100^{\circ} \mathrm{C}$ for $4 \mathrm{hr}$, and then lyophilized.

\section{HPLC}

High pH anion exchange chromatography with pulsed amperometric detection was carried out on an HPLC system from Dionex Corp. The system is described in Hodgins, Butters et al. (2001). The column, a Dionex Carbopac PA-1 $(9 \mathrm{~mm} \times 250 \mathrm{~mm})$ semi-preparative anion exchange column, was run isocratically, at room temperature, in carbonate-free $200 \mathrm{mM} \mathrm{NaOH}$ flowing at $1.7 \mathrm{~mL} / \mathrm{min}$. Carbohydrates were detected using a pulsed amperometric detector (PAD) cell (Dionex PAD-1). The elution times and detector response calibration curves of the chitin-derived carbohydrates N-acetylglucosamine and glucosamine were determined using standards obtained from Sigma-Aldrich. 


\section{Amino Acid Composition Analysis}

Amino acid analysis was carried out on chitin hydrolysates using an Applied Biosystems model 420A derivatizer/analyzer (Foster City, California). Amino acid and amino sugar compositions were determined by precolumn derivatization with phenylisothiocyanate, followed by separation of the phenylthiocarbamyl amino acids and amino sugars by reversed-phase HPLC. The elution of the PTC-derivatized glucosamine standard overlapped with the elution of PTC-asparagine, however, in the chitin hydrolysates, we assumed that the quantity of asparagine would be small compared to that of glucosamine, and so could be disregarded.

\section{Matrix Assisted Laser Desorption Mass Spectrometry}

Mass spectrometric analysis was carried out on unfractionated Otiorhynchus nodosus chitin hydrolysates using a Lasermat Instrument produced by ThermoBioanalysis Ltd. The hydrolyzates were diluted in water to approximately $50 \mathrm{pmol} / \mu \mathrm{L}$ and mixed 1:1 with either DHB or $\alpha$-cyano matrix. One microliter of this mixture was spotted onto aluminium targets and air-dried. The targets were loaded into the instrument, and pulsed with laser light. The resulting vapor was directed into a time of flight mass spectrometer. The principle molecular ion of glucosamine has a m/z ratio of 179 . The mass/charge spectra from hydrolysates were compared to spectra from targets containing the DHB and $\alpha$-cyano matrices alone.

\section{Carbon and Nitrogen Elemental Analysis, Stable Isotope Analysis, and ${ }^{14} \mathrm{C}$-AMS}

All samples were weighed into tin capsules. Combustion and stable isotope measurements were carried out on a Carlo Erba CN Analyzer-Stable isotope Mass Spectrometer and the $\mathrm{CO}_{2}$ recovered for later ${ }^{14} \mathrm{C}$-AMS measurement. ${ }^{14} \mathrm{C}$-AMS was accomplished using the ORAU gas ion source.

\section{RESULTS AND DISCUSSION}

Our original objectives targeted terrestrial herbivore species in an effort to avoid the input of detrital carbon and hard water effects. The site yielded terrestrial and aquatic carnivores and scavengers throughout the section, with herbivorous species recovered only in the lower half of the section.

The mass of individual fragments varied from approximately 50-350 $\mu \mathrm{g}$. This necessitated all measurements being made on pooled samples. Combustion and stable isotope measurement revealed that with one exception, the $\mathrm{CN}$ ratios of the material fell between 6 and 8 (Table 2). Plotted as $\delta^{15} \mathrm{~N}$ versus $\delta^{13} \mathrm{C}$ the values cluster in a manner consistent with a nitrogen trophic level effect (Figure 1). No trends were visible in the shifts in stable isotope values or the $\mathrm{CN}$ ratio as a function of the position within the section.

The AMS dates from plant macrofossils (Carex spp.) appeared to agree with the dates obtained on identical material by Walker et al. (2001). The differences in section thickness made precise comparison difficult. ${ }^{14} \mathrm{C}$ dates obtained from the insect remains were found to be younger than dates from stratigraphically associated seeds (with the exception of a single measurement). The fact that the insect-derived dates were younger argues against explanations based upon the hard water effect or the indirect ingestion of detrital carbon through the ingestion of detritus feeders. The offsets between the AMS dates obtained from the terrestrial herbivore insects and plant macrofossils within the lower layers of the section were not as extreme as the offsets observed by Walker et al. (2001).

The data in Figure 1 indicate a possible trophic level effect within insect chitin $\delta^{15} \mathrm{~N}$ values. However, alternative explanations are possible. A comparison of Figures 1 and 2 suggests a correlation 
Table 2 Insect cuticle $\mathrm{CN}$ ratios and stable isotope values for remains recovered from the St Bees section

\begin{tabular}{llcccc}
\hline Group & Feeding behavior & $\begin{array}{c}\text { Height above } \\
\text { datum }(\mathrm{cm})\end{array}$ & $\begin{array}{c}\text { Atomic } \\
\text { CN ratio }\end{array}$ & $\begin{array}{c}\delta^{13} \mathrm{C} \\
(\% \circ)\end{array}$ & $\begin{array}{r}\delta^{15} \mathrm{~N} \\
(\%)\end{array}$ \\
\hline Dytiscidae & Aquatic carnivores & $30-40$ & 7.0 & -30.3 & 2.4 \\
& & $20-30$ & 6.8 & -29.8 & 2.4 \\
& & $10-20$ & 6.8 & -29.4 & 2.6 \\
Carabidae & Terrestrial & $0-10$ & 6.9 & -30.1 & 2.0 \\
& Carnivores/scavengers & $30-40$ & 6.6 & -26.8 & 3.3 \\
& & $20-30$ & 6.4 & -26.9 & 3.0 \\
& & $10-20$ & 6.5 & -26.3 & 4.0 \\
Barynotus ssp. & Terrestrial herbivores & $5-10$ & 6.7 & -26.9 & 3.5 \\
& & $0-5$ & 7.1 & -27.1 & 3.9 \\
Adoxus obs. & Terrestrial herbivores & $0-15$ & 7.8 & -25.7 & 0.9 \\
& & $10-15$ & 8.7 & -26.3 & 0.5 \\
Donacea vers. & Aquatic herbivores & $0-10$ & 7.7 & -24.3 & -1.5 \\
& & $0-10$ & 7.9 & -24.5 & -1.0 \\
\hline
\end{tabular}

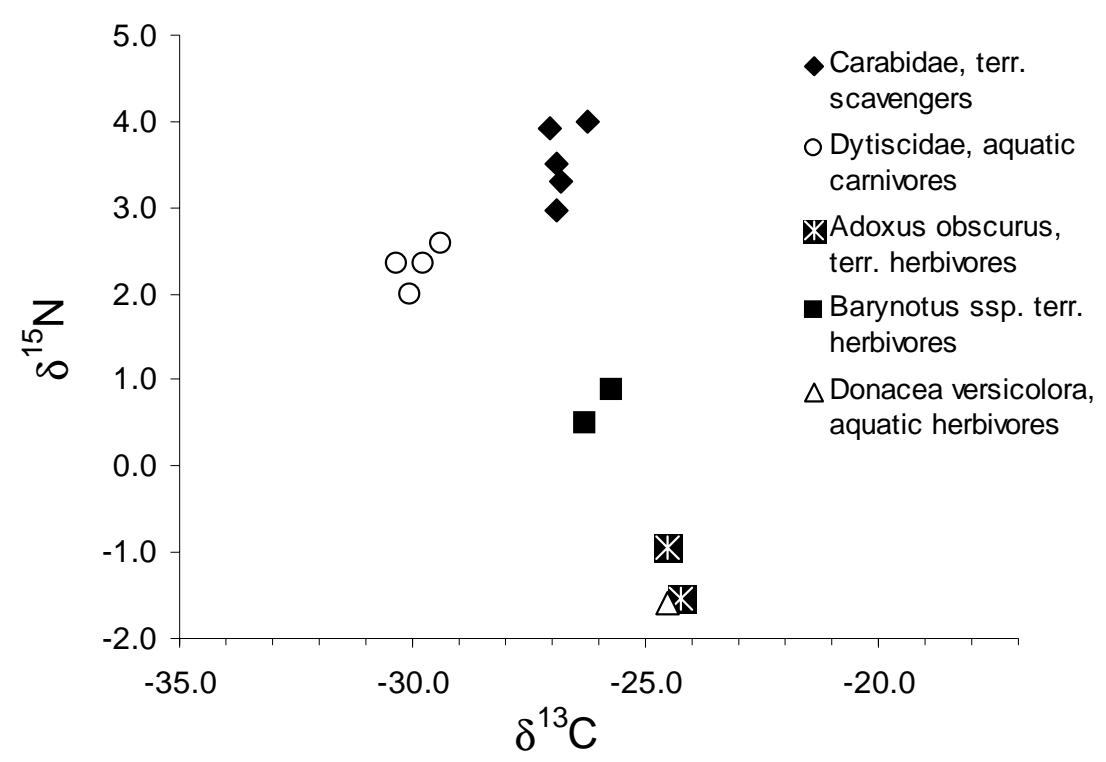

Figure 1 The carbon and nitrogen stable isotope values for St Bees insect remains. The measurement errors are $\delta^{13} \mathrm{C} \pm 0.1 \%$ for carbon and $\delta^{15} \mathrm{~N} \pm 0.3 \%$ or nitrogen. 
between the $\delta^{15} \mathrm{~N}$ values within chitin fractions and the magnitude of the AMS date offset between chitin and plant remains. For example, the Carabid species have both the highest $\delta^{15} \mathrm{~N}$ and the greatest offset from the Carex seed dates. This situation could be explained by the presence of a ${ }^{14} \mathrm{C}$ enriched, ${ }^{15} \mathrm{~N}$-enriched nitrogen-containing contaminant. A comparison of the $\mathrm{CN}$ ratios of the insect fractions (shown in Table 2) and the chitin AMS dates shown in Figure 2 is also consistent with this picture.

Schimmelmann and DeNiro (1986a) pointed out that several factors influence isotopic variability within macromolecular chitin. The acetyl carbon pool is isotopically different than the hexose ring carbon pool, therefore deacetylation during burial and chemical pretreatment will affect $\delta^{13} \mathrm{C}$. They also found that $\delta^{15} \mathrm{~N}$ levels within D-glucosamine purified from arthropod chitin were about $12 \%$ lower than $\delta^{15} \mathrm{~N}$ levels within the muscle mass (Schimmelmann and DeNiro 1986b). Webb (1998) observed a similar spacing in locust tissues. This means that the level of deproteination would influence the $\delta^{15} \mathrm{~N}$ of macromolecular chitin. These effects were measured within fresh chitin. When the contamination from the burial environment is added into the system, the unsuitability of macromolecular chitin for ${ }^{14} \mathrm{C}$ dating becomes clear. Given these factors it is surprising that the isotope values within each group of St Bees insect remains clustered so tightly.

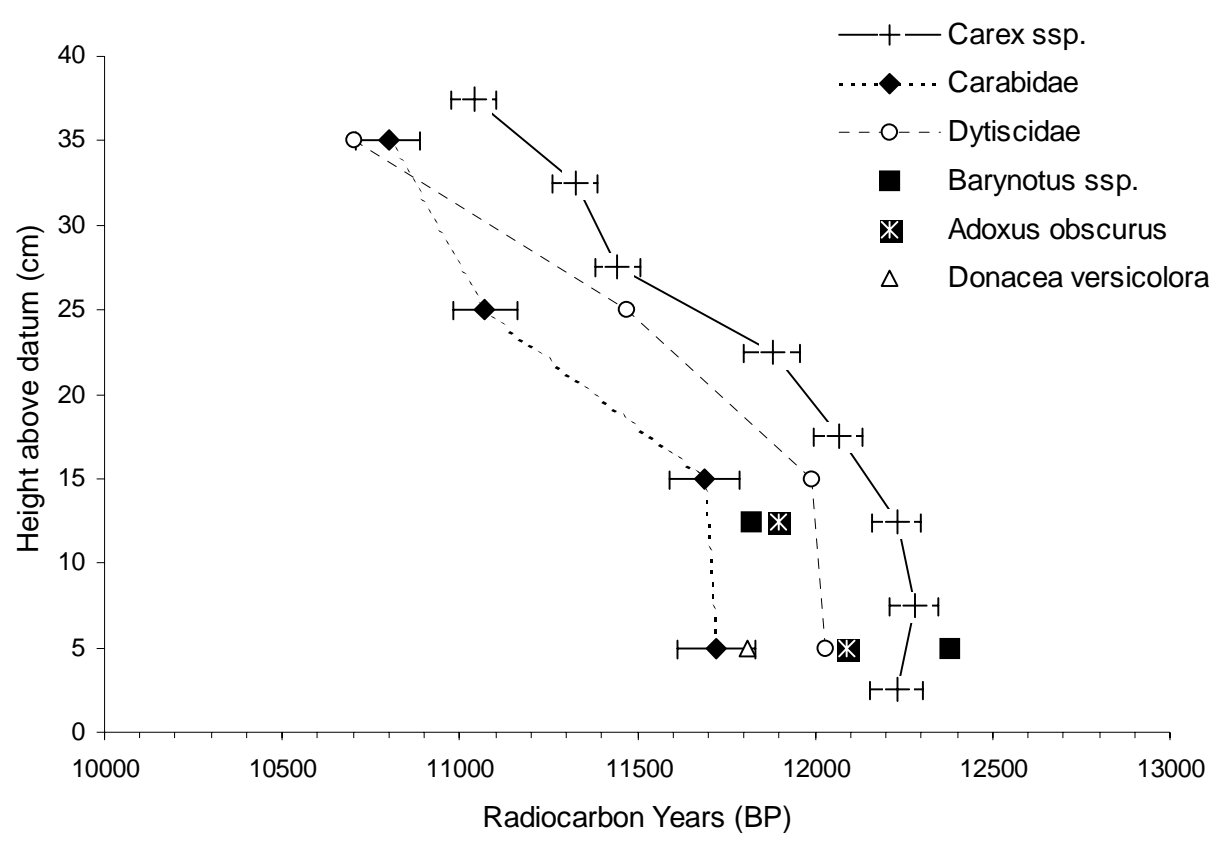

Figure $2{ }^{14} \mathrm{C}$ dates from the St Bees insect remains compared to associated plant macrofossils. The errors of all the insect remains are similar but some have been omitted for clarity. The bars show $1 \sigma$ errors.

\section{Further Purification of the Chitin Fractions}

Schimmelmann and DeNiro (1986a) suggested that the most reliable chitin-derived target compound for stable isotope studies of marine arthropod chitin was glucosamine-HCl. Their protocol included a base hydrolysis step, aimed at de-proteinizing the chitin, followed by mineral acid 
hydrolysis that hydrolyzed the chitin polymer and deacetylated $\mathrm{N}$-acetylglucosamine to glucosamine-HCl. The glucosamine monomer was separated from the resulting amino acids using Dowex-50 W-X8 ion exchange resin run in $1 \mathrm{~N} \mathrm{HCl}$. We investigated their protocol using St Bees insect remains and utililized analytical high $\mathrm{pH}$ anion exchange chromatography instead of cation exchange.

Five-milligram batches of insect remains from St Bees and Redkirk Point were carried through solvent, acid extraction, deproteinization, and chitin hydrolysis steps. Various deproteinization protocols were investigated; namely combinations of proteinase $\mathrm{K}$ treatment and hot alkaline hydrolysis. The mass of chitin/chitosan after each stage was measured directly until the hydrolysis step. After hydrolysis glucosamine was quantified by analytical high $\mathrm{pH}$ anion exchange chromatography, as well as by derivatization with phenylisothiocyanate followed by reverse phase HPLC. The results in Figure 3 shows that $5-10 \%$ of the starting mass was soluble in organic solvents, and another $10 \%$ of the mass removed by $1 \mathrm{~N} \mathrm{HCl}$ hydrolysis. Thirty to $50 \%$ of the mass was removed by alkaline hydrolysis in combination with proteinase $\mathrm{K}$ treatment. This result generally agreed with the observations of Miller et al. (1993) that 41-55\% of chitin mass was proteinaceous in material of a similar age. Regardless of the method of deproteinization, only $5 \%$ of the starting mass was recovered as glucosamine monomer.

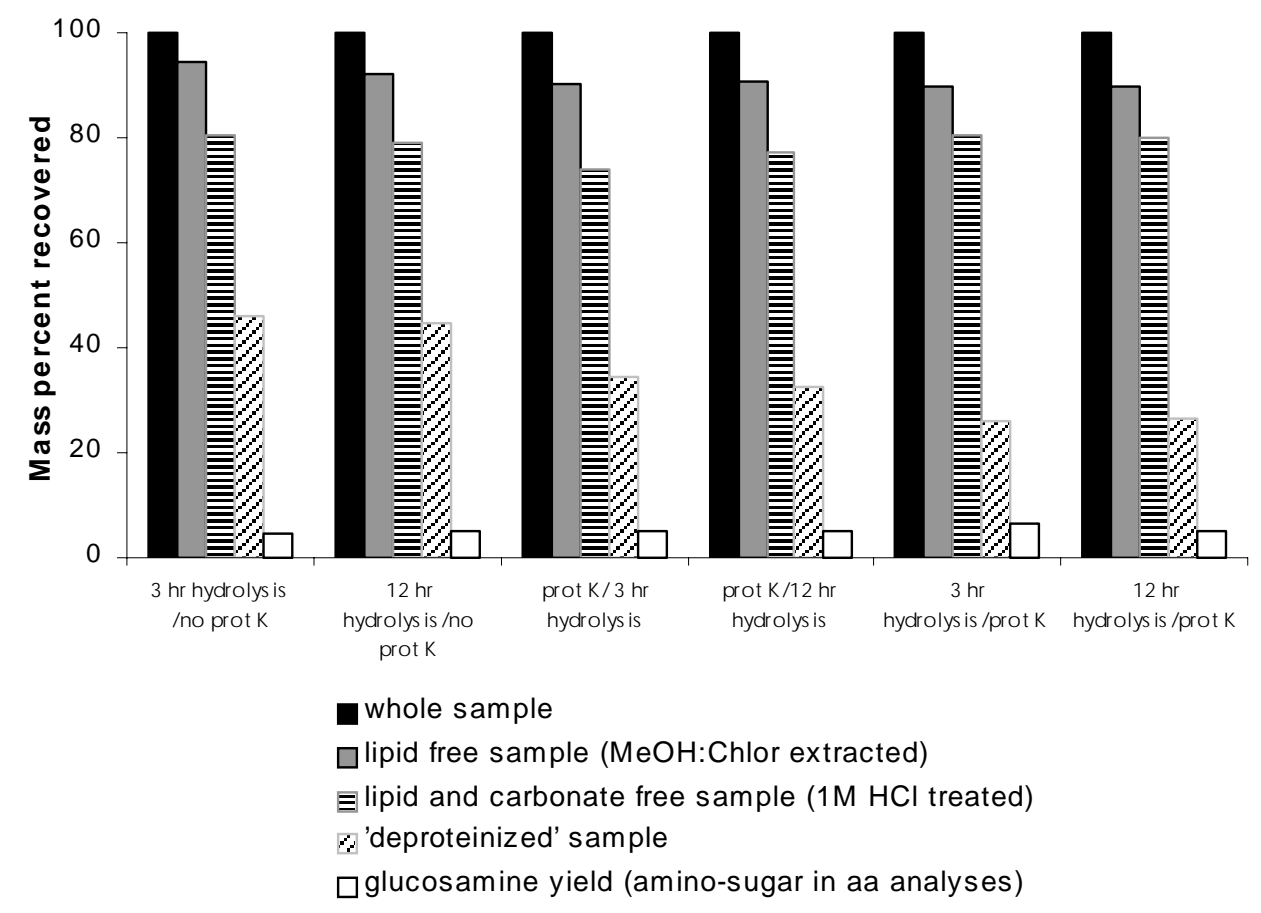

Figure 3 The effect of different extraction protocols on six aliquots of insect chitin recovered from St Bees, Cumbria. Two and one half milligram aliquots were treated sequentially with solvents, $1 \mathrm{~N} \mathrm{HCl}$, and the either $1 \mathrm{~N} \mathrm{NaOH}$ alone or $1 \mathrm{~N} \mathrm{NaOH}$ combined with proteinase $\mathrm{K}$ digestion as described in the Materials and Methods. Glucosamine yields were determined chromatographically, using pulsed amperometric detection, or UV absorption after phenylisothiocarbamyl derivatization. 
Hydrolysis, phenylisothiocarbamyl derivatization and reverse phase HPLC of the "deproteinized" chitin revealed that $3 \mathrm{hr}$ in $1 \mathrm{~N} \mathrm{NaOH}$ at $100{ }^{\circ} \mathrm{C}$ (followed by water rinsing), still left amino acids within the structure that accounted for one quarter of the remaining mass. This value was reduced to approximately $1 / 10$ the remaining mass if 12 -hr incubations with $1 \mathrm{~N} \mathrm{NaOH}$ were used. Although it is possible that the yield of glucosamine in the chitin hydrolysates has been reduced due to basecatalysed epimerization of glucosamine to mannosamine, the so-called Lobry de Bruyn-van Ekenstein transformation (see Pigman 1957), the fact that the HPLC resolved essentially a single principle component suggests the epimerization reaction is not significant.

Matrix-assisted laser desorption mass spectrometry was also carried out on four of the six chitin hydrolysates. A single peak was common to all and this had a mass/charge ratio of 179 , the ratio expected for the principle molecular ion of glucosamine (not shown).

Using the remains of Otiorhynchus nodosus recovered from the Redkirk Point site, we investigated how different purification protocols affected elemental ratios, stable isotope values and ${ }^{14} \mathrm{C}$ date, and compared these to the published dates obtained from surrounding organic material (Table 3). The large changes in $\mathrm{CN}$ ratios and stable isotope values compared to the relatively small changes in ${ }^{14} \mathrm{C}$ date throughout the purification argue against Redkirk Point being the appropriate site for protocol development. Shown graphically in Figure 4, only methanol/chloroform solvent washes were required to bring the dates in line with all subsequent fractions. Initially these appeared to be systematically offset from the bulk material based upon the published BIRM-41date. However, repeating the measurement on peat from the site (OxA-9499) indicated that the insect remains and peat were contemporary. The offset seen in the St Bees material was not evident at Redkirk Point.

The purification of $\mathrm{N}$-acetylglucosamine and glucosamine from insect remains for the purpose of compound-specific dating does not currently appear practical because the yield of specific compound after chitin hydrolysis is so low. It is likely that the presence of substantial quantities of amino acids within the cuticle structure even after "deproteinization" promotes the formation of Maillard reaction products during the chitin hydrolysis step. In an associated study (Hodgins et al. 2001), we have been investigating enzymatic methods of carbohydrate polymer hydrolysis and purification using wood cellulose as a model system. This study has shown significant increases in monomer yield over acid hydrolysis. Future experiments on the purification of insect remains will be directed towards investigating the efficiency of chitinase-mediated hydrolysis.

Table 3 Changes in chitin chemistry during pre-treatment for ${ }^{14} \mathrm{C}$ dating

\begin{tabular}{|c|c|c|c|c|c|c|}
\hline $\begin{array}{l}\text { O. nodosus } \\
\text { fraction: }\end{array}$ & $\begin{array}{l}\text { Starting } \\
\text { mass }(\mathrm{mg})\end{array}$ & $\begin{array}{l}\text { Atomic } \\
\mathrm{CN} \text { ratio }\end{array}$ & $\begin{array}{l}\delta^{13} \mathrm{C} \\
(\% o)\end{array}$ & $\begin{array}{l}\delta^{15} \mathrm{~N} \\
(\% o)\end{array}$ & $\begin{array}{c}\text { Uncal. } \\
\text { date (BP) }\end{array}$ & $\begin{array}{c}\text { Error } \\
( \pm)\end{array}$ \\
\hline Untreated & 4.1 & 8.5 & -25.7 & 1.8 & 11390 & 70 \\
\hline Solvent & 5.2 & 14.5 & -24.7 & -0.9 & 11670 & 65 \\
\hline Solvent/acid & 4.2 & 9.1 & -25.9 & 2.8 & 11665 & 65 \\
\hline $\begin{array}{l}\text { Solvent/acid/ } \\
\text { alkaline/acid }\end{array}$ & 11.8 & 7.8 & -24.3 & -0.5 & 11645 & 119 \\
\hline $\begin{array}{l}\text { Redkirk Point peat: } \\
(\text { BIRM-41) }\end{array}$ & & & & & 11205 & 177 \\
\hline (OxA-9499) & & & -26.9 & & 11690 & 65 \\
\hline
\end{tabular}

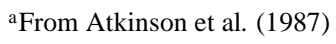




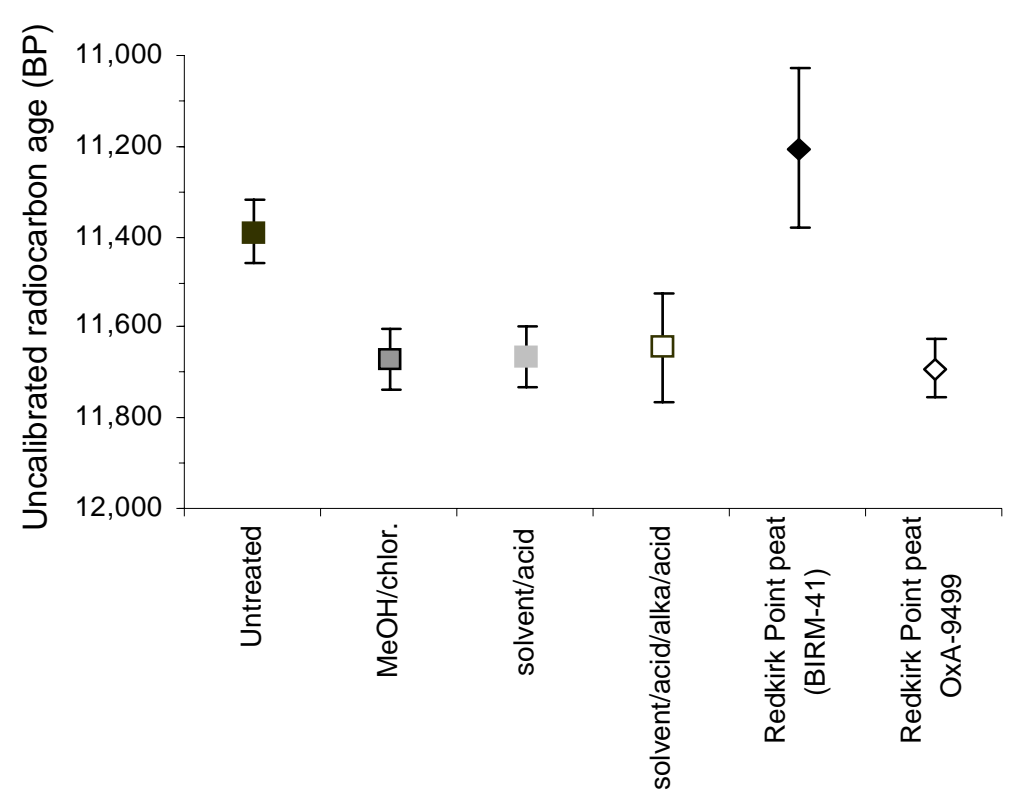

Figure $4{ }^{14} \mathrm{C}$ dates from various fractions of Otiorhynchus nodosus obtained from Redkirk Point compared to dates from bulk organic material

\section{CONCLUSIONS}

The observed dating offset between sub-fossil insect remains and surrounding organic material was shown to be influenced by chemical pretreatment protocols. The offset was not completely eliminated after the isolation of macromolecular chitin, suggesting that either further chitin purification is necessary, or some biological/ecological explanation must be put forward.

Sub-fossil insects with different feeding behaviors displayed nitrogen stable isotopic values reminiscent of trophic levels seen in other terrestrial ecosystems. However, the demonstration of variability in $\mathrm{CN}$ ratios and residual amino acids within the chitin preparations indicated that further purification would be necessary before firm conclusions could be reached.

Shimmelmann and DeNiro (1986a) demonstrated that the CN ratio and carbon and nitrogen stable isotope values are not reliable criteria for macromolecular chitin purity for several reasons. There is inherent variability in the carbohydrate composition. The principle carbohydrate $\mathrm{N}$-acetylglucosamine is susceptible to acid hydrolysis. It is difficult to fully "deproteinize" the sample and this combined with a large spacing between chitin and protein stable nitrogen isotope values means that residual peptides within the chitin structure have a large affect on the measurement.

We have investigated the feasibility of purifying monomer carbohydrates from sub-fossil chitin. We found that only $5 \%$ of the cuticle mass can be detected as monomer carbohydrate in acid hydrolysates. Clearly, sample recovery is the greatest hurdle. Chitinase enzymolysis is being investigated as an alternative, and parallel experiments on enzymolysis of cellulose have been encouraging. 


\section{ACKNOWLEDGMENTS}

We thank the staff of ORAU for assisting with the stable isotope analysis and ${ }^{14} \mathrm{C}$ measurements, and Mr Anthony Willis and Dr T Butters for assistance with the amino acid analysis and carbohydrate characterization.

\section{REFERENCES}

Aalbersberg G, Litt T. 1998. Multiproxy climate reconstructions for the Eemian and early Weichselian. Journal of Quaternary Science 13(5):367-90.

Atkinson TC, Briffa KR, Coope GR. 1987. Seasonal temperatures in Britain during the past 22,000 years, reconstructed using beetle remains. Nature 325: 587 92.

Bishop WW, Coope GR. 1977. Stratigraphical and faunal evidence for lateglacial and early Flandrian environments in south west Scotland. In: JM Gray, JJ Lowe, editors. The Scottish Lateglacial Environment, Pergamon Press. Oxford. p. 61-88.

Coope GR, Lemdahl G, Lowe JJ, Walking A. 1998. Temperature gradients in northern Europe during the last glacial-Holocene transition $\left(14-9{ }^{14} \mathrm{C}\right.$ kyr BP) interpreted from coleopteran assemblages. Journal of Quaternary Science 13(5):419-33.

DeNiro MJ, Epstein S. 1981. Influence of diet on the distribution of nitrogen isotopes in animals. Geochimica et Cosmochimica Acta. 45:341-51.

Elias SA, Carrara PE, Toolin LJ, Jull AJT. 1991. Revised age of deglaciation of Lake Emma based on new radiocarbon and macrofossil analysis. Quaternary Research 36:307-21.

Elias SA, Toolin LJ. 1990. Accelerator dating of mixed assemblage of late Pleistocene insect fossils from the Lamb Spring site, Colorado. Quaternary Research 33: 122-6.

Hedges REM, Law I, Bronk CR, Housley RA. 1989. The Oxford accelerator mass spectrometry facility: technical developments in routine dating Archaeometry 31(2):99-114.

Hodgins GWL, Butters TD, Bronk Ramsey C, Hedges REM. 2001. The chemical and enzymatic hydrolysis of archaeological wood cellulose and monosaccharide purification by high $\mathrm{pH}$ anion exchange chromatography for compound-specific radiocarbon dating. $R a-$ diocarbon. This issue.

Miller RF, Voss-Foucart M-F, Toussaint C, Jeuniaux C. 1993. Chitin preservation in Quaternary Coleoptera: preliminary results. Palaeogeography, Palaeoclima- tology, Palaeoecology 103:133-40.

Morris MG. 1997. Broad-nosed weevils, Coleoptera: curculionidae (Entiminae). In: WR Dolling, RR Askew, editors. Handbook for the identification of British insects, Vol. 5, Part 17a. London: Royal Entomological Society, p 14-22.

Peter MG, Kegel G, Keller R. 1986. Structural studies on sclerotized insect cuticle. In: Muzarelli RAA, Jeuniaux $\mathrm{C}$, Gooday $\mathrm{GW}$, editors. Chitin in nature and technology. New York: Plenum Publishing Corporation, p 21-8.

Pigman WW. 1957. The carbohydrates. New York: Academic Press, p 60.

Richards AG. 1978. The chemistry of insect cuticle. In: Rockstein M, editor. Biochemistry of insects. New York: Academic Press, p 205-32.

Schimmelman A, DeNiro MJ. 1986a Stable isotopic studies on chitin I. Measurements on chitin/chitosan isolates and D-glucosamine hydrochloride from chitin. In: Muzarelli RAA, Jeuniaux C, Gooday GW, editors. Chitin in nature and technology. New York: Plenum Publishing Corporation, p 357-64.

Schimmelman A, DeNiro MJ. 1986b Stable isotopic studies on chitin II. The ${ }^{13} \mathrm{C} /{ }^{12} \mathrm{C}$ and ${ }^{15} \mathrm{~N} /{ }^{14} \mathrm{~N}$ ratios in arthropod chitin. Contributions in Marine Science 29: 113-30.

Stankiewicz BA, Briggs DEG, Evershed RP, Duncan IJ. 1997a Chemical preservation of insect cuticle from the Pleistocene asphalt deposits of California, USA. Geochimica et Cosmochimica Acta 61(11):2247-52.

Stankiewicz BA, Briggs DEG, Evershed RP, Flannery MB, Wuttke M. 1997b. Preservation of Chitin in 25million-year-old fossils. Science 276:1541-43.

Walker MJC, Bryant C, Coope GR, Harkness DD, Lowe JJ, Scott EM. 2001. Towards a radiocarbon chronology for the late-glacial in Britain. Radiocarbon. This issue.

Webb S. 1998. Stable Carbon and Nitrogen isotopes in Insects: the influence of diet. D.Phil Thesis. University of Oxford. 